\title{
Clinical presentation and outcome of venous thromboembolism in COPD
}

\author{
L. Bertoletti*,\#,ฯ, S. Quenet*, P. Mismetti*,\#,ף, L. Hernández ${ }^{+}$, \\ J.J. Martín-Villasclaras ${ }^{\S}$, C. Tolosa ${ }^{f}$, M. Valdés**, M. Barrón ${ }^{\# \#, ~}$ \\ J.A. Todolí ${ }^{\dagger}$, M. Monreal ${ }^{++}$and the RIETE Investigators ${ }^{\S \S}$
}

ABSTRACT: Chronic obstructive pulmonary disease (COPD) is a moderate risk factor for venous thromboembolism (VTE), but neither the clinical presentation nor the outcome of VTE in COPD patients is well known.

The clinical presentation of VTE, namely pulmonary embolism (PE) or deep venous thrombosis (DVT), and the outcome at 3 months (death, recurrent VTE or bleeding) were compared between 2,984 COPD patients and 25,936 non-COPD patients included in the RIETE (Registro Informatizado de la Enfermedad TromboEmbólica) registry. This ongoing international, multicentre registry includes patients with proven symptomatic PE or DVT.

PE was the more frequent VTE presentation in COPD patients $(n=1,761,59 \%)$. PE presentation was more significantly associated with COPD patients than non-COPD patients (OR 1.64, 95\% CI 1.49-1.80). During the 3-month follow-up, mortality (10.8\% versus $7.6 \%)$, minor bleeding $(4.5 \%$ versus $2.3 \%)$ or first VTE recurrences as PE (1.5\% versus $1.1 \%)$ were significantly higher in COPD patients than in non-COPD patients. PE was the most common cause of death.

COPD patients presented more frequently with PE than DVT. It may explain the worse prognosis of COPD patients, with a higher risk of death, bleeding or VTE recurrences as PE compared with non-COPD patients. Further therapeutic options are needed.

KEYWORDS: Chronic obstructive pulmonary disease, deep venous thrombosis, prognosis, pulmonary embolism, venous thromboembolism

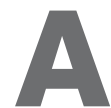
cute pulmonary embolism (PE) and deep venous thrombosis (DVT) are manifestations of the overall disease known as venous thromboembolism (VTE). Epidemiological studies have demonstrated that DVT is the most frequent clinical presentation of VTE in general settings, with nearly two presentations of DVT to every one presentation of PE $[1,2]$. However, this clinical presentation may be influenced by certain risk factors. For example, total knee replacement surgery is a well-known predisposing factor for DVT [3]. Chronic obstructive pulmonary disease (COPD) is a moderate predisposing factor for VTE, principally when associated with hospitalisation [3]. Post hoc analyses of administrative healthcare databases using diagnostic codes suggest that the increased risk of VTE in COPD patients may be predominantly manifested in the form of PE rather than DVT [4-7]. An increased expression of VTE as PE in COPD patients may be problematic since the mortality of COPD patients with PE is particularly high $[8,9]$, and COPD has been integrated in prognostic scores such as the Simplified Pulmonary Embolism Severity Index [10]. COPD has also been associated with inappropriate management in the case of suspected PE [11] and the suggestion of PE may be challenging in COPD patients [12] because of the similarities in symptoms. The former consideration may particularly apply during COPD exacerbation [13-15], a situation in which undiagnosed PE was found in an autopsy study in up to $30 \%$ of COPD patients who died [16]. Finally, COPD has been associated with an increased risk of unsuspected fatal PE [17]. Confirming the increased rate of PE in COPD patients should prompt clinicians to enhance PE suspicion in COPD patients at risk for VTE.

The RIETE (Registro Informatizado de la Enfermedad TromboEmbólica) registry is an ongoing international (Spain, France, Italy, Israel, Switzerland and Germany), multi-centre prospective registry of consecutive patients presenting with
AFFILIATIONS

${ }^{*}$ Thrombosis Research Group, EA3065, Université de Saint-Etienne, \#INSERM, CIE3,

- Service de Médecine Interne et Thérapeutique, Hôpital Nord, CHU de Saint-Etienne, Saint-Etienne, France. +Dept of Pneumonology, Hospital General Universitario de Alicante, Alicante,

${ }^{\S}$ Dept of Pneumonology, Hospital General Universitario Carlos Haya, Malaga,

'Dept of Internal Medicine Corporación Sanitaria Parc Taulí, Sabadell,

${ }^{\star *}$ Dept of Internal Medicine, Hospital Viladecans, Viladencans,

\#\#Dept of Pneumonology, Complejo Hospitalario San Millán y San Pedro, Logroño,

"Dept of Internal Medicine, Hospital Universitario La Fe, Valencia,

${ }^{+}$Dept of Internal Medicine, Hospital Universitari Germans Trias i Pujol, Badalona, Spain.

${ }^{\S \S}$ For a full list of RIETE investigators, see the Acknowledgements.

\section{CORRESPONDENCE}

L. Bertoletti

Groupe de Recherche sur la

Thrombose, EA3065

Université de Saint-Etienne 42000 Saint-Etienne

France

E-mail: laurent.bertoletti@gmail.com

Received:

April 052011

Accepted after revision:

Aug 082011

First published online:

Sept 012011 
symptomatic acute VTE. Data from this registry have been used to evaluate outcomes after acute VTE, such as the frequency of recurrent VTE, bleeding and mortality, and risk factors for these outcomes [18-20]. We then conducted this study with two goals: 1) to check whether COPD patients really present more frequently with PE rather than DVT; and 2) to define the clinical characteristics and outcome of COPD patients with VTE, compared with patients with VTE but without COPD. We were especially interested to determine whether COPD influences a patient's risk of dying from PE or bleeding during treatment.

\section{MATERIALS AND METHODS}

\section{Registry design}

The RIETE registry is an ongoing international, multi-centre prospective cohort of consecutive patients with symptomatic, objectively confirmed acute VTE (DVT, PE or both). Patients are managed according to the clinical practice of each participating hospital centre and followed up for at least 3 months. There are only two exclusion criteria: a planned follow-up of $<3$ months and participation in a therapeutic clinical trial. For this analysis, only patients aged $>18$ yrs were considered.

At each participating centre, a registry coordinator controlled the quality of data collection (e.g. internal validity and coherence) and recorded the data from each patient on a computer-based case report form. Coordinators ensured that all consecutive patients with confirmed VTE were included in the registry. In addition, the database used for each analysis was controlled. The information was then transferred online, via a secure website, to the study coordinating centre responsible for data management. Data quality was also monitored by members of contract research organisations, who compared the data on medical records with the data transferred online during periodic visits to the participating hospitals. All patients gave written consent to their participation in the registry, in accordance with the requirements of the ethics committee of each country. Death (and cause of death), bleeding and VTE recurrence during the follow-up were adjudicated by the RIETE registry coordinators.

\section{Study outcomes}

Baseline characteristics, thrombosis risk factors (including the presence of COPD) and clinical presentation of VTE (PE with or without DVT and DVT without any symptomatic PE) were recorded at baseline. In patients with acute respiratory symptoms suggesting PE, symptomatic PE was confirmed if it was objectively documented (by positive helical computed tomography scan, high-probability ventilation/perfusion lung scan, positive pulmonary angiography, visualisation of a thrombus in the right ventricle or in the right atrium on echocardiography, or intermediate-probability ventilation/ perfusion lung scan associated with a diagnosis of DVT). DVT was diagnosed in the case of acute symptoms of DVT confirmed by compression ultrasound or contrast venography of the lower limbs. The following information was also collected: demographic data, symptoms on presentation, types and results of diagnostic methods, and risk factors for VTE. Immobilised patients were defined as non-surgical patients who had been immobilised for $\geqslant 4$ days during the 2-month period prior to VTE diagnosis. Surgical patients were defined as those who had undergone an operation within the 2 months prior to VTE. Patients were categorised as obese if their body mass index (BMI) was $\geqslant 30 \mathrm{~kg} \cdot \mathrm{m}^{-2}$. The presence of COPD was assessed by the treating physician.

Information on treatment and outcome (i.e. occurrence of death, major bleeding, minor bleeding or another objectively confirmed VTE event) was recorded at day 7 and during the 3-month follow-up period. If the patient died, death was considered to be due to PE if this diagnosis had been documented at autopsy, or if the patient died shortly after objectively confirmed symptomatic PE, and in the absence of any alternative diagnosis. Bleeding complications were classified as "major" if they were overt and required a transfusion of two or more units of blood, or were retroperitoneal, spinal, intracranial or fatal. Other types of bleeding were classified as "minor". Each recurrent VTE event was objectively confirmed using the same criteria as the index VTE event. Every event was adjudicated by the RIETE registry coordinators.

\section{Data analysis}

Qualitative data were reported as n (\%). Quantitative data were reported as median (interquartile range). A logistic regression model was used to examine the individual relationship between each variable and the presence of COPD. The selection of variables was based on the literature and on expert opinion. Any variable achieving a p-value $<0.15$ on univariate analysis was included in a multivariate logistic regression analysis. Odds ratios and the corresponding 95\% confidence intervals were calculated. Some COPD patients may experience a high rate of exacerbation leading to non-surgical immobilisation [21], a type of immobilisation not applicable to non-COPD patients, by definition. Therefore, we considered two immobilisation variables: 1) all-cause immobilisation, and 2) immobilisation excluding immobilisation for COPD exacerbation. The cumulative rates of death, VTE and bleeding were estimated by the Kaplan-Meier method and compared between COPD and non-COPD patients by the log-rank test. A p-value $\leqslant 0.05$ was considered to be statistically significant. Data were processed and analysed using SAS for Windows ${ }^{\mathrm{TM}}$ software (version 9.13; SAS Institute Inc., Cary, NC, USA).

\section{RESULTS}

Between March 2001 and October 2009, a total of 28,920 consecutive adult patients with objectively confirmed acute VTE were included in the RIETE registry. Of these, 2,984 $(10.3 \%)$ were diagnosed as having COPD.

\section{Clinical characteristics and VTE presentation in COPD and non-COPD patients}

In the univariate analyses (table 1) COPD was significantly associated with male sex, with a male:female ratio of 2:1 in the COPD group. COPD patients were also significantly older, half of them being $\geqslant 75$ yrs of age. Obesity was associated to a slightly greater extent with COPD. Regarding thrombosis risk factors, no difference in VTE history was found between COPD and non-COPD patients. COPD exacerbation was the main reason for immobilisation, accounting for approximately onethird of the immobilisation causes in COPD patients, followed by acute infection. Taken together, exacerbation and infection prompted $50 \%$ of non-surgical immobilisations among COPD patients. 
TABLE 1 Patient characteristics at baseline, thrombosis risk factors and index venous thromboembolism (VTE) event for 2,984 chronic obstructive pulmonary disease (COPD) versus 25,936 non-COPD patients with VTE

\begin{tabular}{|c|c|c|c|c|}
\hline & COPD & Non-COPD & Univariate analysis ${ }^{\#}$ & Multivariate analysis ${ }^{\#}$ \\
\hline \multicolumn{5}{|l|}{ Characteristics } \\
\hline Males & 2005 (67.2) & $12216(47.1)$ & $2.30(2.12-2.49)$ & $2.72(2.46-3.01)$ \\
\hline Age yrs & $75(68-80)$ & $70(55-78)$ & & \\
\hline Age $\geqslant 75$ yrs & $1503(50.4)$ & $9519(36.7)$ & $1.75(1.62-1.89)$ & $2.08(1.89-2.29)$ \\
\hline Cancer & $600(20.1)$ & $5534(21.3)$ & $0.93(0.84-1.02)$ & $0.88(0.79-0.99)$ \\
\hline Surgery in the last 2 months & $239(8.0)$ & $3321(12.8)$ & $0.59(0.52-0.68)$ & $0.67(0.57-0.80)$ \\
\hline Immobilisation & 968 (32.4) & $6303(24.3)$ & & \\
\hline COPD exacerbation & $308(32)$ & NA & & \\
\hline Trauma without surgery & $88(9)$ & $1290(21)$ & & \\
\hline Acute infection & $208(21)$ & $843(13)$ & & \\
\hline Others & $163(17)$ & $1659(26)$ & & \\
\hline Thromboprophylaxis & $306(32)$ & $1492(23.7)$ & & \\
\hline Immobilisation ${ }^{+}$ & $660(22.1)$ & $6303(24.3)$ & $0.88(0.81-0.97)$ & $0.89(0.80-1.00)$ \\
\hline \multicolumn{5}{|l|}{ Index VTE event } \\
\hline Symptomatic PE & $1761(59.0)$ & $12314(47.4)$ & $1.59(1.47-1.72)$ & $1.64(1.49-1.80)$ \\
\hline
\end{tabular}

Data are presented as $n(\%), n / N(\%)$ or odds ratio (95\% confidence interval). Data for age is presented as median (interquartile range). BMI: body mass index; PE; pulmonary embolism; NA: not available; NS: nonsignificant. ${ }^{*}$ : COPD versus non-COPD; ${ }^{\circ}$ : prolonged immobilisation ( $\geqslant 4$ days) for any non-surgical reason; ${ }^{+}:$excluding that for COPD exacerbation.

Regarding VTE presentation, PE (with or without DVT) was the most frequent initial clinical presentation of VTE in COPD patients $(1,761$ out of 2,$984 ; 59 \%)$. In the univariate analysis, COPD patients presented with PE more frequently than nonCOPD patients.

In the multivariate analysis (table 1), male sex, age $>75$ yrs and obesity remained positively associated with COPD, whereas surgery, cancer and immobilisation for non-surgical reasons (excluding COPD exacerbations) were more weakly associated with COPD. COPD remained associated with a higher risk of PE presentation than in non-COPD patients (OR $1.64,95 \%$ CI $1.49-1.80)$.

\section{Therapeutic strategies}

Regarding initial VTE treatment, COPD patients received thrombolytics $(1 \%)$ or inferior vena cava filter $(1.6 \%)$ less often than non-COPD patients (1.5\% and $2.3 \%$, respectively). During the 3-month follow-up, COPD patients were more frequently treated with vitamin $\mathrm{K}$ antagonists $(76 \%)$ than non-COPD patients $(73 \%)$, and inversely less treated with low-molecular weight heparin ( $24 \%$ versus $28 \%$ ) (table 2 ).

\section{Early and 3-month clinical outcomes}

At day 7 (table 3), the overall mortality was significantly higher in COPD patients $(2.6 \%)$ than in non-COPD patients $(1.7 \% ; \log$-rank $p=0.001)$. PE was the cause of death in the vast majority of COPD patients (52 out of 78 deaths). There were slightly more VTE recurrences in COPD patients $(0.6 \%)$ than in non-COPD patients $(0.4 \%)$ but the difference was not statistically significant (log-rank $p=0.09$ ). There were more VTE recurrences as $\mathrm{PE}$ in COPD patients $(0.6 \%)$ than in non-COPD patients $(0.3 \% ; \mathrm{p}=0.02)$. There was no statistically significant difference between the groups with regard to the cumulative incidence of major bleeding at day $7(0.8 \%$ versus $0.8 \%$, logrank $\mathrm{p}=0.76$ ), but COPD patients had a higher 7-day

\section{TABLE 2 Therapeutic strategies}

\begin{tabular}{lccc} 
& COPD & Non-COPD & p-value \\
\hline $\begin{array}{l}\text { Patients } \mathbf{n} \\
\text { Initial therapy }\end{array}$ & 2984 & 25936 & \\
$\quad$ & & \\
$\quad$ LMWH & $2773(93)$ & $24197(93)$ & 0.45 \\
$\quad$ Unfractionated heparin & $254(8.5)$ & $2168(8.4)$ & 0.77 \\
$\quad$ Thrombolytics & $30(1.0)$ & $375(1.5)$ & 0.053 \\
$\quad$ Inferior vena cava filter & $48(1.6)$ & $607(2.3)$ & 0.011 \\
Long-term therapy & & & \\
$\quad$ LMWH & $722(24)$ & $7152(28)$ & $<0.001$ \\
$\quad$ Vitamin K antagonists & $2273(76)$ & $19047(73)$ & 0.001 \\
\hline
\end{tabular}

Data are presented as $\mathrm{n}(\%)$, unless otherwise stated. COPD: chronic obstructive pulmonary disease; LMWH: low-molecular weight heparin. 


\begin{tabular}{|c|c|c|c|}
\hline & COPD & No n-COPD & $p$-value \\
\hline Patients n & 2984 & 25936 & \\
\hline \multicolumn{4}{|l|}{ Outcome } \\
\hline Recurrent VTE & $18(0.6)$ & $103(0.4)$ & 0.09 \\
\hline As DVT ${ }^{\#}$ & $1(0.03)$ & $24(0.1)$ & 0.30 \\
\hline As $\mathrm{PE}^{\#}$ & $17(0.6)$ & $79(0.3)$ & 0.02 \\
\hline \multicolumn{4}{|l|}{ Bleeding } \\
\hline Major & $25(0.8)$ & $205(0.8)$ & 0.76 \\
\hline Minor & $46(1.6)$ & $159(0.6)$ & $<0.0001$ \\
\hline Overall death & $78(2.6)$ & $438(1.7)$ & 0.001 \\
\hline \multicolumn{4}{|l|}{ Causes of death } \\
\hline$P E^{*}$ & $52(1.7)$ & $245(1.0)$ & \\
\hline Bleeding & $4(0.1)$ & $29(0.1)$ & \\
\hline Disseminated cancer & $1(0.03)$ & $45(0.2)$ & \\
\hline Sudden/unexpected & 0 & $3(0.01)$ & \\
\hline Respiratory insufficiency & $7(0.2)$ & $18(0.1)$ & \\
\hline Heart failure & $2(0.1)$ & $12(0.05)$ & \\
\hline Infection & $6(0.2)$ & $30(0.1)$ & \\
\hline Myocardial infarction & 0 & $2(0.01)$ & \\
\hline Ischaemic stroke & 0 & $3(0.01)$ & \\
\hline Other & $6(0.2)$ & $51(0.2)$ & \\
\hline
\end{tabular}

Data ate presented as $n(\%)$, unless otherwise stated. COPD: chronic obstructive pulmonary disease; VTE: venous thromboembolism; DVT: deep venous thrombosis; PE: pulmonary embolism. ${ }^{\#}$ : only the first recurrent event is presented; ": including initial fatal PE and fatal PE during the follow-up.

cumulative incidence of minor bleeding $(1.6 \%$ versus $0.6 \%$, logrank $\mathrm{p}<0.0001$ ).

At 3 months (table 4), the cumulative incidence of mortality was significantly higher in VTE patients with COPD $(10.8 \%)$ than in VTE patients without COPD $(7.6 \%$; log-rank $\mathrm{p}<0.0001)$ (fig. 1). The main cause of death was PE (2.3\%), followed by respiratory insufficiency, disseminated cancer (both 1.6\%) and infection $(1.2 \%)$. Global rate of VTE recurrence was similar between COPD and non-COPD patients (table 4). However, the incidence of VTE recurrences as PE during the 3-month follow-up was significantly higher in COPD patients than in non-COPD patients $(1.5 \%$ versus $1.1 \%$; log-rank $\mathrm{p}=0.04)$, whereas the incidence of VTE recurrences as DVT was significantly lower $(0.7 \%$ versus $1.1 \%$; log-rank $p=0.05)$. There was no statistically significant difference between the groups with regard to the cumulative incidence of major bleeding at 3 months $(2.7 \%$ versus $2.2 \%$; log-rank $p=0.16)$, but COPD patients had a higher 3-month cumulative incidence of minor bleeding $(4.5 \%$ versus $2.3 \%$; log-rank $\mathrm{p}<0.0001)$.

\section{DISCUSSION}

These data, obtained from a multi-centre clinical registry of consecutive patients with confirmed symptomatic VTE, provide important information about the clinical characteristics of COPD patients presenting with acute symptomatic VTE. We confirm that COPD patients with acute symptomatic VTE present more frequently with PE than with DVT $(59 \%$ versus $41 \%$ ), with a $60 \%$ increase in the risk of presenting with $\mathrm{PE}$ rather than DVT compared to non-COPD patients with VTE.

\begin{tabular}{|c|c|c|c|}
\hline & COPD & No $n$-COPD & $p$-value \\
\hline Patients n & 2984 & 25936 & \\
\hline \multicolumn{4}{|l|}{ Outcome } \\
\hline Recurrent VTE ${ }^{\#}$ & $63(2.2)$ & $547(2.2)$ & 0.89 \\
\hline As $\mathrm{DVT}^{\#}$ & $20(0.7)$ & $280(1.1)$ & 0.05 \\
\hline As $P E^{\#}$ & $43(1.5)$ & $267(1.1)$ & 0.04 \\
\hline \multicolumn{4}{|l|}{ Bleeding } \\
\hline Major & $76(2.7)$ & $564(2.2)$ & 0.16 \\
\hline Minor & $127(4.5)$ & 567 (2.3) & $<0.001$ \\
\hline Overall death & $322(10.8)$ & $1970(7.6)$ & $<0.001$ \\
\hline \multicolumn{4}{|l|}{ Causes of death } \\
\hline$P E^{*}$ & $69(2.3)$ & $373(1.4)$ & \\
\hline Bleeding & $19(0.6)$ & $153(0.6)$ & \\
\hline Disseminated cancer & $48(1.6)$ & $574(2.2)$ & \\
\hline Sudden/unexpected & $6(0.2)$ & $25(0.1)$ & \\
\hline Respiratory insufficiency & $47(1.6)$ & $96(0.4)$ & \\
\hline Heart failure & $11(0.4)$ & $61(0.2)$ & \\
\hline Infection & $36(1.2)$ & $182(0.7)$ & \\
\hline Myocardial infarction & $2(0.1)$ & $9(0.03)$ & \\
\hline Ischaemic stroke & $2(0.1)$ & $19(0.07)$ & \\
\hline Other & $80(2.7)$ & $478(1.8)$ & \\
\hline
\end{tabular}

Data ate presented as $n(\%)$, unless otherwise stated. COPD: chronic obstructive pulmonary disease; VTE: venous thromboembolism; DVT: deep venous thrombosis; PE: pulmonary embolism. ${ }^{\#}$ : only the first recurrent event is presented; " including initial fatal PE and fatal PE during the follow-up.

COPD patients also have a worse 3-month prognosis than nonCOPD patients, with higher rates of death, VTE recurrences as $\mathrm{PE}$ and minor bleeding.

\section{Main results}

The predominance of males and older patients in the COPD group is easily understood as the prevalence of COPD increases with age and the expected male:female ratio in COPD patients $>65$ yrs of age is 2:1 [22]. Obesity was found to be slightly more prevalent in COPD patients than in nonCOPD patients with VTE, with a median BMI of $27 \mathrm{~kg} \cdot \mathrm{m}^{-2}$ and a BMI $>30 \mathrm{~kg} \cdot \mathrm{m}^{-2}$ in $30 \%$ of COPD patients with VTE. Obesity is a well-known risk factor for VTE [23]. Of note, the prevalence of obesity in our COPD patients with VTE was two-fold higher than that observed in a large primary care population of European patients with COPD [24]. The lower rate of surgery in COPD patients is easily explained by the fragility of these patients, for whom conservative options may generally be preferred.

We confirmed the results of post hoc analyses of administrative healthcare data [4-7], finding an increased presentation of VTE as PE in COPD patients. It is possible that PE was more frequently searched for (and found) in COPD patients. By definition, COPD patients present with respiratory symptoms, which can enhance the suspicion of PE. However, the chronicity and variability of symptoms, as well as the frequent exacerbations, may conversely decrease the suspicion of PE in some COPD patients. Thus, FERNANDEZ et al. [25] found that COPD patients diagnosed with PE were more likely to 


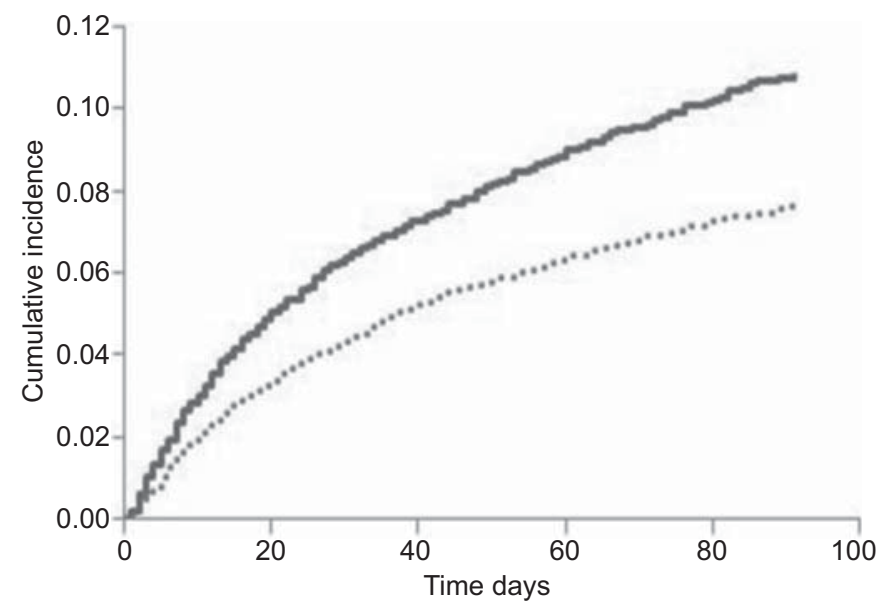

FIGURE 1. Kaplan-Meier curve of 3-month overall mortality in chronic obstructive pulmonary disease (COPD: - - ) and non-COPD $(\cdots \cdots \cdots)$ patients.

experience a longer delay before diagnosis than non-COPD patients. PINEDA et al. [17] found that COPD was associated with a higher risk of unsuspected fatal PE. Therefore, we cannot rule out a possible under diagnosis of PE in COPD patients, but this would rather strengthen our results.

Concerning outcome during the 3-month follow-up, the higher mortality in the COPD group is in accordance with previous studies, in which COPD was associated with a poorer prognosis [26]. This difference is already present at day 7, mainly because of PE-related death. Interestingly, more aggressive treatment, such as thrombolytics or inferior vena cava filters, have been less frequently used in COPD patients with VTE.

We did not find any statistically significant difference in the risk of major bleeding between COPD and non-COPD patients, although such a difference has been evoked in smaller studies [27]. The higher rate of minor bleeding may be explained by the co-prescription of drugs such as steroids or anti-platelets, which may increase the bleeding risk in COPD patients. Moreover, COPD patients were older than non-COPD patients, and this may also account for the differences.

\section{Main limitations}

Our study has several limitations. Some are due to the RIETE registry design. By definition, all patients included presented symptomatic and objectively confirmed VTE. However, they were diagnosed according to the clinical practice of each participating centre. Therefore, we cannot exclude the possibility that some patients classified as having DVT in fact had asymptomatic and/or undiagnosed PE. This clinical classification is nevertheless frequently employed, even in randomised controlled therapeutic trials. Therefore, our results cannot be extended to COPD patients with undiagnosed PE. PE may also have been underestimated in COPD patients presenting with signs of DVT and acute respiratory symptoms, as respiratory symptoms are spontaneously attributed to COPD without any screening for PE. Undiagnosed recurrent PE may explain, in part, the high rate of mortality due to PE.

In addition, results of lung function tests were not available for all our COPD patients. Diagnosis of COPD was based solely on the clinical information available to the investigator. Patients may, therefore, have been misclassified as COPD or non-COPD. This lack of lung function tests is unfortunately shared by many studies on this topic [28-31]. For example, data on lung function were available for only $28 \%$ of the patients included in a recent study of acute exacerbation of COPD [29]. However, the prevalence of COPD in the RIETE registry is similar to that in general settings [32], as mentioned previously. Moreover, COPD is usually underdiagnosed so if there was any misclassification, this would be under diagnosis (i.e. classification of undiagnosed COPD patients as non-COPD patients) than over diagnosis [32]. Furthermore, we could not subdivide COPD patients according to different stages of severity.

Clinical impact, unanswered questions and future research The clinical characteristics of COPD patients with VTE shown by our study may partly explain the difference between studies searching for PE during COPD exacerbation. The patients included in the study of RUTSCHMANN et al. [33] were more similar to ours, in terms of age and sex ratio, than those included in the studies of Tillie-LeBLOND et al. [34] and GUNEN et al. [35]. Similarly, the rates of past VTE (25\%) or active cancer $(43 \%)$ were much higher in the study of TILLIE-LEBLOND et al. [34] than in our VTE series. Selection bias may explain these differences, resulting in contradictory results.

Our results may also be viewed in a physiological perspective. Recent studies established that COPD may induce an additional specific pro-thrombotic biological situation, particularly during acute exacerbation of COPD [36, 37]. It is worth noting that only one-third of immobilised COPD patients with VTE received thrombosis prophylaxis during immobilisation. Therefore, efforts to improve thromboprophylaxis use are needed. Elsewhere, links between obesity, adipokines and the abnormal inflammatory response seen in COPD are currently debated [38] and the potential effect of these interactions on pro-thrombotic states in COPD patients deserves further research. Moreover, the pulmonary arteries of COPD patients are characterised by endothelial cell dysfunction [39] and the hypothetical COPDrelated pro-thrombotic status may predominate with regard to the pulmonary vascular bed, leading to in situ thrombosis [40].

Finally, more aggressive VTE treatments, such as thrombolytics or placement of a vena cava filter, have been proposed for COPD patients, particularly those presenting with DVT [30], but we found them to be less frequently used in our COPD patients. Inferior vena cava filters might protect the reduced pulmonary vascular bed of COPD patients from PE, which constitutes the main presentation of VTE in COPD patients according to our results, without any increase in the bleeding risk. However, if we consider that PE may sometimes be an in situ thrombosis rather than an embolic complication of a DVT, placement of a vena cava filter might not be appropriate in the former case.

\section{Conclusion}

Our study is the largest clinical study to date focusing on clinical presentation and outcome of VTE in COPD patients. We confirmed that PE is more frequently diagnosed in COPD patients, and that such patients have a poorer prognosis than non-COPD patients, with higher rates of mortality and minor bleeding. Treatment with higher efficiency on recurrence risk but with no increase in bleeding risk deserves further evaluation. 


\section{SUPPORT STATEMENT}

L. Bertoletti was supported by a research grant from Collège des Enseignants de Pneumologie.

\section{STATEMENT OF INTEREST}

A statement of interest for the study itself can be found at www.erj. ersjournals.com/site/misc/statement.xhtml

\section{ACKNOWLEDGEMENTS}

The RIETE registry coordinator is M. Monreal (Dept of Internal Medicine, Hospital Universitari Germans Trias I Pujol, Badalona, Spain); the Steering Committee members of RIETE are H. Decousus (France), P. Prandoni (Italy) and B. Brenner (Israel); and the RIETE national coordinators are R. Barba (Spain), P. Di Micco (Italy), L. Bertoletti (Thrombosis Research Group, EA3065, Université de SaintEtienne, Saint Etienne, France), M. Papadakis (Greece), M. Bosevski (Republic of Macedonia) and H. Bounameaux (Switzerland).

The members of RIETE are as follows. Spain: M. Alcalde, J.I. Arcelus, M.P. Arcos, R. Barba, M. Barrón, A. Blanco-Molina, J. Bosco, T. Cámara, M. Calvo, I. Casado, J.M. Casas, E. Cisneros, E. Chaves, F. Conget, C. Delgado, J. del Toro, M. Durán, C. Falgá, C. Fernández-Capitán, M. Ferreiro, C. Font, F. Gabriel, P. Gallego, F. García-Bragado, M. Guil, N. Guillém, J. Gutiérrez, M.J. Hermosa, L. Hernández, D. HernándezHuerta, F. Hernández-Toboso, M.J. Jaras, D. Jiménez, S. Jiménez, M. Jiménez-Gil, R. Lecumberri, J.L. Lobo, L. López-Jiménez, A. Lorenzo, J.M. Luque, O. Madridano, A. Maestre, V. Manzano, P.J. Marchena, J.J. Martín-Villasclaras, M. Monreal, R. Monte, M. Morales, S. Muñoz, M.D. Nauffal, J.A. Nieto, J.L. Ogea, M. Oribe, R. Otero, J.M. Pedrajas, R. Rabuñal, A. Riera-Mestre, M.A. Rodríguez-Dávila, M. Román, P. Román, B. Román-Bernal, V. Rosa, S. Rubio, J. Ruíz, A. Ruiz-Gamietea, N. Ruiz-Giménez, J.C. Sahuquillo, A. Samperiz, R. Sánchez, J.F. Sánchez Muñoz-Torrero, S. Soler, M.J. Soto, G. Tiberio, J.A. Tolodí, C. Tolosa, M.I. Torres, J. Trujillo, F. Uresandi, M. Valdés, V. Valdés, R. Valle, G. Vidal, J. Villalta and V. Zorrilla; France: L. Bertoletti, A. BuraRiviere, P. Debourdeau, I. Mahe and K. Rivron-Guillot; Greece: M. Papadakis; Israel: B. Brenner and D. Zeltser; Italy: A. Barillari, G. Barillari, M. Ciammaichella, P. Di Micco, F. Dalla Valle, R. Duce, R. Maida, S. Pasca, C. Piovella, R. Poggio, P. Prandoni, R. Quintavalla, A. Rocci, A. Schenone, E. Tiraferri, D. Tonello, A. Visonà and B. Zalunardo; Republic Of Macedonia: M. Bosevski; Switzerland: H. Bounameaux and M. Righini.

The authors would like to thank S. Laporte (St-Etienne, France) and A. Perrier (Geneva, Switzerland) for their intellectual input and critical revisions, and all RIETE members for including patients. We express our gratitude to Sanofi-Aventis Spain for supporting this Registry with an unrestricted educational grant. We also express our gratitude to Bayer Pharma AG for supporting this Registry. Bayer Pharma AG's support was limited to the part of RIETE outside Spain, which accounts for a $13.39 \%$ of the total patients included in the RIETE Registry. We also thank the Registry coordinating centre (S and H Medical Science Service, Madrid, Spain) for their quality control, and logistical and administrative support. L. Bertoletti would like to thank the "Collège des Enseignants de Pneumologie" who provided a research grant.

\section{REFERENCES}

1 Cohen AT, Agnelli G, Anderson FA, et al. Venous thromboembolism (VTE) in Europe. The number of VTE events and associated morbidity and mortality. Thromb Haemost 2007; 98: 756-764.

2 Oger E. Incidence of venous thromboembolism: a communitybased study in Western France. EPI-GETBP Study Group. Groupe d'Etude de la Thrombose de Bretagne Occidentale. Thromb Haemost 2000; 83: 657-660.

3 Torbicki A, Perrier A, Konstantinides S, et al. Guidelines on the diagnosis and management of acute pulmonary embolism: the Task Force for the Diagnosis and Management of Acute
Pulmonary Embolism of the European Society of Cardiology (ESC). Eur Heart J 2008; 29: 2276-2315.

4 Stein PD, Beemath A, Meyers FA, et al. Pulmonary embolism and deep venous thrombosis in hospitalized adults with chronic obstructive pulmonary disease. J Cardiovasc Med (Hagerstown) 2007; 8: 253-257.

5 Sidney S, Sorel M, Quesenberry CP Jr, et al. COPD and incident cardiovascular disease hospitalizations and mortality: Kaiser Permanente Medical Care Program. Chest 2005; 128: 2068-2075.

6 Schneider C, Bothner U, Jick SS, et al. Chronic obstructive pulmonary disease and the risk of cardiovascular diseases. Eur $\mathrm{J}$ Epidemiol 2010; 25: 253-260.

7 Curkendall SM, DeLuise C, Jones JK, et al. Cardiovascular disease in patients with chronic obstructive pulmonary disease, Saskatchewan Canada cardiovascular disease in COPD patients. Ann Epidemiol 2006; 16: 63-70.

8 Carson JL, Terrin ML, Duff A, et al. Pulmonary embolism and mortality in patients with COPD. Chest 1996; 110: 1212-1219.

9 Zielinski J, MacNee W, Wedzicha J, et al. Causes of death in patients with COPD and chronic respiratory failure. Monaldi Arch Chest Dis 1997; 52: 43-47.

10 Jimenez D, Aujesky D, Moores L, et al. Simplification of the pulmonary embolism severity index for prognostication in patients with acute symptomatic pulmonary embolism. Arch Intern Med 2010; 170: 1383-1389.

11 Roy PM, Meyer G, Vielle B, et al. Appropriateness of diagnostic management and outcomes of suspected pulmonary embolism. Ann Intern Med 2006; 144: 157-164.

12 Bertoletti L, Righini M. Adequate use of pulmonary embolism clinical prediction rule in COPD patients. Eur Respir J 2011; 37: 219-220.

13 Akram AR, Cowell GW, Logan LJ, et al. Clinically suspected acute pulmonary embolism: a comparison of presentation, radiological features and outcome in patients with and without PE. QJM 2009; 102: 407-414.

14 Lesser BA, Leeper KV Jr, Stein PD, et al. The diagnosis of acute pulmonary embolism in patients with chronic obstructive pulmonary disease. Chest 1992; 102: 17-22.

15 Bertoletti L, Mismetti P, Decousus H. The cloud of pulmonary embolism during COPD exacerbation. Thorax 2011; [Epub ahead of print DOI: 10.1136/thoraxjnl-2011-200416].

16 Neuhaus A, Bentz RR, Weg JG. Pulmonary embolism in respiratory failure. Chest 1978; 73: 460-465.

17 Pineda LA, Hathwar VS, Grant BJ. Clinical suspicion of fatal pulmonary embolism. Chest 2001; 120: 791-795.

18 Monreal M, Munoz-Torrero JF, Naraine VS, et al. Pulmonary embolism in patients with chronic obstructive pulmonary disease or congestive heart failure. Am J Med 2006; 119: 851-858.

19 Laporte S, Mismetti P, Decousus H, et al. Clinical predictors for fatal pulmonary embolism in 15,520 patients with venous thromboembolism: findings from the Registro Informatizado de la Enfermedad TromboEmbolica venosa (RIETE) Registry. Circulation 2008; 117: 1711-1716.

20 Ruiz-Gimenez N, Suarez C, Gonzalez R, et al. Predictive variables for major bleeding events in patients presenting with documented acute venous thromboembolism. Findings from the RIETE Registry. Thromb Haemost 2008; 100: 26-31.

$21 \mathrm{Xu} \mathrm{W}$, Collet J-P, Shapiro S, et al. Negative impacts of unreported COPD exacerbations on health-related quality of life at 1 year. Eur Respir J 2010; 35: 1022-1030.

22 Gershon AS, Wang C, Wilton AS, et al. Trends in chronic obstructive pulmonary disease prevalence, incidence, and mortality in Ontario, Canada, 1996 to 2007: a population-based study. Arch Intern Med 2010; 170: 560-565.

23 Stein PD, Beemath A, Olson RE. Obesity as a risk factor in venous thromboembolism. Am J Med 2005; 118: 978-980. 
24 Steuten LM, Creutzberg EC, Vrijhoef HJ, et al. COPD as a multicomponent disease: inventory of dyspnoea, underweight, obesity and fat free mass depletion in primary care. Prim Care Respir J 2006; 15: 84-91.

25 Fernandez C, Jimenez D, De Miguel J, et al. Enfermedad pulmonar obstructiva cronica en pacientes con tromboembolia de pulmon aguda sintomatica [Chronic obstructive pulmonary disease in patients with acute symptomatic pulmonary embolism]. Arch Bronconeumol 2009; 45: 286-290.

26 Sanchez O, Trinquart L, Caille V, et al. Prognostic factors for pulmonary embolism: the prep study, a prospective multicenter cohort study. Am J Respir Crit Care Med 2010; 181: 168-173.

27 Nijkeuter M, Sohne M, Tick LW, et al. The natural course of hemodynamically stable pulmonary embolism: clinical outcome and risk factors in a large prospective cohort study. Chest 2007; 131: 517-523.

28 Hartmann IJ, Hagen PJ, Melissant CF, et al. Diagnosing acute pulmonary embolism: effect of chronic obstructive pulmonary disease on the performance of D-dimer testing, ventilation/ perfusion scintigraphy, spiral computed tomographic angiography, and conventional angiography. ANTELOPE Study Group. Advances in New Technologies Evaluating the Localization of Pulmonary Embolism. Am J Respir Crit Care Med 2000; 162: 2232-2237.

29 Murio C, Soler X, Perez M, et al. Acute exacerbation of chronic obstructive pulmonary disease in primary care setting in Spain: the EPOCAP study. Ther Adv Respir Dis 2010; 4: 215-223.

30 Shetty R, Seddighzadeh A, Piazza G, et al. Chronic obstructive pulmonary disease and deep vein thrombosis: a prevalent combination. J Thromb Thrombolysis 2008; 26: 35-40.

31 Sohne M, Kruip MJ, Nijkeuter M, et al. Accuracy of clinical decision rule, D-dimer and spiral computed tomography in patients with malignancy, previous venous thromboembolism, COPD or heart failure and in older patients with suspected pulmonary embolism. J Thromb Haemost 2006; 4: 1042-1046.

32 Halbert RJ, Natoli JL, Gano A, et al. Global burden of COPD: systematic review and meta-analysis. Eur Respir J 2006; 28: 523-532.

33 Rutschmann OT, Cornuz J, Poletti PA, et al. Should pulmonary embolism be suspected in exacerbation of chronic obstructive pulmonary disease? Thorax 2007; 62: 121-125.

34 Tillie-Leblond I, Marquette $\mathrm{CH}$, Perez $\mathrm{T}$, et al. Pulmonary embolism in patients with unexplained exacerbation of chronic obstructive pulmonary disease: prevalence and risk factors. Ann Intern Med 2006; 144: 390-396.

35 Gunen H, Gulbas G, In E, et al. Venous thromboemboli and exacerbations of COPD. Eur Respir J 2010; 35: 1243-1248.

36 Sabit R, Thomas P, Shale DJ, et al. The effects of hypoxia on markers of coagulation and systemic inflammation in patients with COPD. Chest 2010; 138: 47-51.

37 Vaidyula VR, Criner GJ, Grabianowski C, et al. Circulating tissue factor procoagulant activity is elevated in stable moderate to severe chronic obstructive pulmonary disease. Thromb Res 2009; 124: 259-261.

38 Tkacova R. Systemic inflammation in chronic obstructive pulmonary disease: may adipose tissue play a role? Review of the literature and future perspectives. Mediators Inflamm 2010; 2010: 585989.

39 Voelkel NF, Cool CD. Pulmonary vascular involvement in chronic obstructive pulmonary disease. Eur Respir J 2003; 22: Suppl. 46, 28s-32s.

40 Russo A, De Luca M, Vigna C, et al. Central pulmonary artery lesions in chronic obstructive pulmonary disease: a transesophageal echocardiography study. Circulation 1999; 100: 1808-1815. 